\title{
Author Correction: HAWC observations of the acceleration of very-high-energy cosmic rays in the Cygnus Cocoon
}

A. U. Abeysekara, A. Albert, R. Alfaro, C. Alvarez, J. R. Angeles Camacho, J. C. Arteaga-Velázquez, K. P. Arunbabu (D, D. Avila Rojas, H. A. Ayala Solares (D), V. Baghmanyan, E. Belmont-Moreno, S. Y. BenZvi, R. Blandford (D, C. Brisbois, K. S. Caballero-Mora, T. Capistrán (D), A. Carramiñana, S. Casanova (D, U. Cotti, S. Coutiño de León (D), E. De la Fuente (D), R. Diaz Hernandez, B. L. Dingus, M. A. DuVernois, M. Durocher (D), J. C. Díaz-Vélez ID, R. W. Ellsworth, K. Engel (D), C. Espinoza D , K. L. Fan, K. Fang (D), H. Fleischhack (D), N. Fraija D , A. Galván-Gámez DD, D. Garcia, J. A. García-González, F. Garfias, G. Giacinti (D), M. M. González ID, J. A. Goodman (D), J. P. Harding, S. Hernandez, J. Hinton, B. Hona (D), D. Huang, F. Hueyotl-Zahuantitla (D), P. Hüntemeyer (D), A. Iriarte, A. Jardin-Blicq (D), V. Joshi, D. Kieda (D), A. Lara (D), W. H. Lee, H. León Vargas (D), J. T. Linnemann, A. L. Longinotti, G. Luis-Raya, J. Lundeen, K. Malone (D), O. Martinez, I. Martinez-Castellanos, J. Martínez-Castro, J. A. Matthews, P. Miranda-Romagnoli, J. A. Morales-Soto, E. Moreno D, M. Mostafá (D), A. Nayerhoda, L. Nellen, M. Newbold, M. U. Nisa, R. Noriega-Papaqui, L. Olivera-Nieto, N. Omodei (D, A. Peisker, Y. Pérez Araujo, E. G. Pérez-Pérez, Z. Ren D, C. D. Rho, D. Rosa-González, E. Ruiz-Velasco, H. Salazar, F. Salesa Greus (D), A. Sandoval, M. Schneider, H. Schoorlemmer, F. Serna, A. J. Smith, R. W. Springer, P. Surajbali, K. Tollefson, I. Torres (D), R. Torres-Escobedo, F. Ureña-Mena, T. Weisgarber, F. Werner, E. Willox (iD, A. Zepeda, H. Zhou, C. De León (iD and J. D. Álvarez

Correction to: Nature Astronomy https://doi.org/10.1038/s41550-021-01318-y, published online 11 March 2021.

In the version of this Letter originally published, the white text in Fig. 1 had a drop-shadow effect that could have been mistaken for data; the effect has now been removed and the original and corrected versions of Fig. 1 are shown below. Furthermore, in the key of Fig. 2b, the unit in the label for the black triangles was incorrectly given as TeV and should have been GeV; this has now been corrected. All versions of the Letter have been amended. 


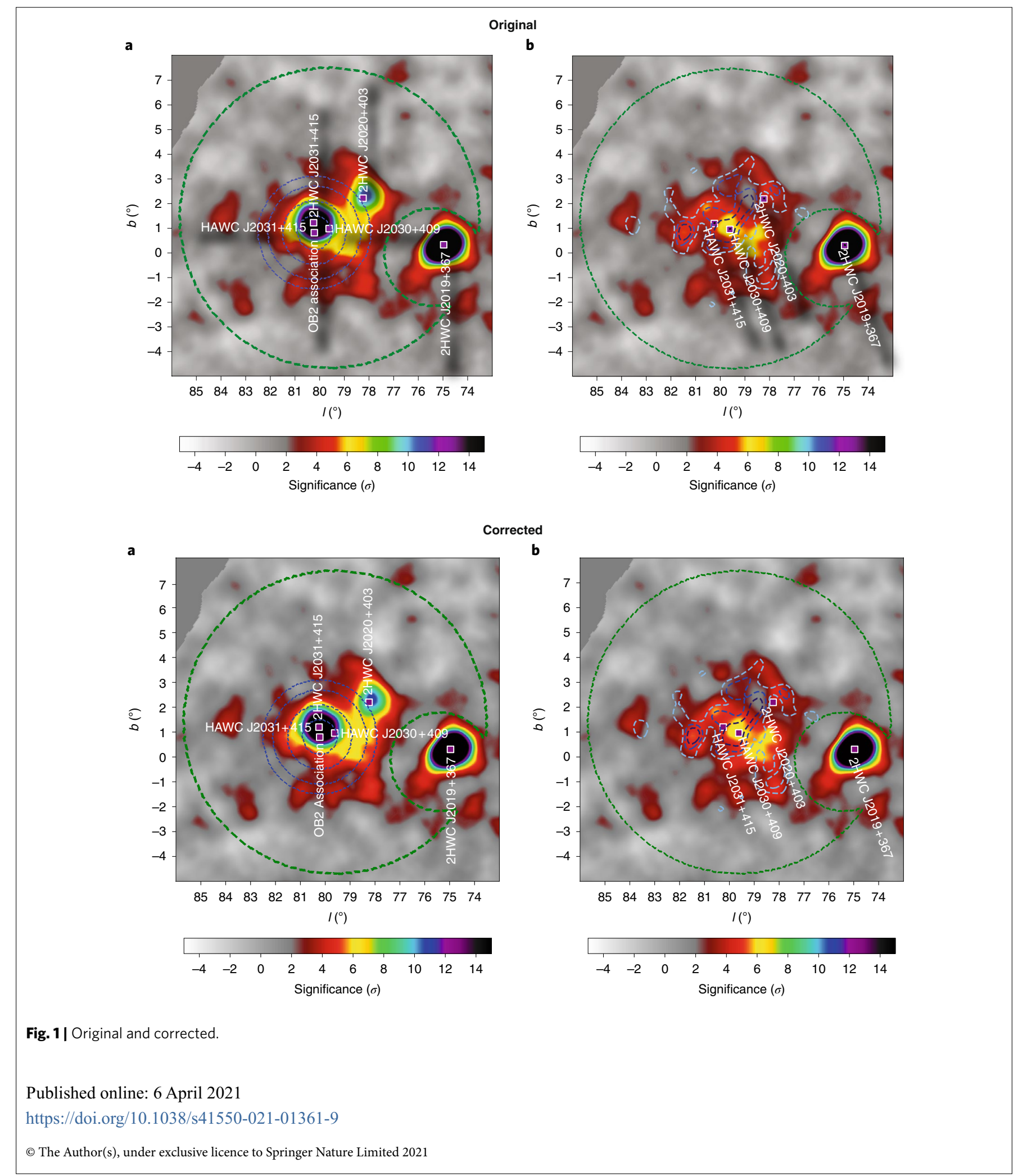

